\title{
Commentary
}

\section{Making the Case for a Female-Friendly Toilet}

\author{
Margaret L. Schmitt ${ }^{1, *}$, David Clatworthy ${ }^{2}$ (D) , Tom Ogello $^{2}$ and Marni Sommer ${ }^{1, *}$ \\ 1 Mailman School of Public Health, Columbia University, New York, NY 10032, USA \\ 2 International Rescue Committee, New York, NY 10168, USA; David.Clatworthy@rescue.org (D.C.); \\ tom.ogello@rescue.org (T.O.) \\ * Correspondence: maggieschmitt@gmail.com (M.L.S.); marni.sommer@columbia.edu (M.S.)
}

Received: 25 July 2018; Accepted: 21 August 2018; Published: 5 September 2018

\begin{abstract}
Inadequate access to a private, comfortable, and well-located toilet remains a critical challenge for many girls and women around the world. This issue is especially acute for girls and women living in densely populated urban slums, displacement camps, and informal settlements, often resulting in anxiety, embarrassment, discomfort, and gender-based violence. The unique sanitation needs of girls and women are rarely accounted for during the design and construction of toilet facilities, including needs related to their physiology, reproductive health processes, prevalent social norms, and their heightened vulnerability to violence. It is critical that a new norm be developed regarding the design of female-friendly toilets which better enables girls and women to feel confident, safe, and dignified while managing their daily sanitation needs. This includes adopting specific design measures which account for their menstrual hygiene, personal safety, and dignity-related needs. Ultimately, an enhanced dialogue must take place among designers, policy makers, water, sanitation, and hygiene (WASH) practitioners, and other relevant actors, in addition to the target female users themselves, about how to adapt toilets in a range of development and emergency contexts and operations to better address these critical needs of girls and women.
\end{abstract}

Keywords: gender and sanitation; menstruation; menstrual hygiene management; water; water, sanitation and hygiene (WASH); waste management

\section{Introduction}

One of the most pervasive yet common forms of gender discrimination experienced daily by girls and women around the world is their inadequate access to a private, comfortable, and convenient toilet. Although men and women both share the critical need for adequate access to toilets, a range of social, cultural, and biological realities often impact and differentiate their sanitation experiences, including their ability to advocate and address these sanitation needs. Girls and women living in low-resource rural and urban areas within development and humanitarian contexts, especially those dwelling in densely populated urban slums, displacement camps, and informal settlements, suffer even more from constrained access to an adequate toilet, resulting in experiences of stress [1-4], embarrassment [5-7], physical discomfort, and gender-based violence [8-10].

More recently, topics of "potty parity," "period equity", and "toilet insecurity" have gained traction within global-level gender and development dialogues [11-15]. Such concepts have been linked to advocacy efforts promoting sanitation and gender issues around the world through platforms like "World Toilet Day" and "Menstrual Hygiene Day." The "period equity" movement largely focuses on advocating for menstrual health needs, primarily access to menstrual products $[12,15-17]$ in high-income countries, while the discourse concerning "toilet insecurity" is focused on generating better evidence about the negative health and psychosocial impact of poor toilet access for girls and women in low- and middle-income country contexts [1,3,14]. 
Despite the rise of these critical advocacy and research efforts, far too little has been done globally with respect to improving the design, guidelines, and placement (within a given location) of toilets that specifically support girls and women. This includes the testing of new ideas and systems regarding the concept of a female-friendly toilet. For example, most toilets accessed by girls and women in low-resource and emergency contexts continue to lack integral design measures for managing their menstruation and other sanitation needs comfortably and with dignity, including easy access to water and soap, safety measures (locks, doors, gender segregation, and lights) and a mechanism for discreetly handling menstrual waste (Box 1). The lack of consideration for a female's distinct sanitation needs may be related to the predominance of males in the water and sanitation engineering fields who are responsible for toilet design [18]. As non-menstruators and with differing bodily needs, their perspectives on toilet design may be limited. However, even female water and sanitation engineers, despite their own experiences with menstruation, may not always appreciate the specific needs that girls and women have in relation to toilet design, given longstanding established norms and standards related to current toilet design [19].

\section{Box 1. What is a female-friendly toilet?}

A safe and conveniently located toilet, separated by gender (if communal or public), which provides privacy (doors, locks), a culturally appropriate menstrual waste disposal option (trash bins, chutes, pits), water and soap is available for washing blood off one's hands (water tap or bucket), suitable drainage and accessibility both during the day and night (area and internal lighting) (see Figure 1).

In addition, actual consultation with girls and women regarding their sanitation needs is relatively rare $[1,20,21]$. This is particularly the case in humanitarian contexts where emergency responders' baseline knowledge about the cultural sanitation practices and needs of displaced females may be low $[5,22,23]$. Consultation with girls and women is often further hindered by strong taboos linked to menstruation and general discomfort discussing female sanitation. Furthermore, societal expectations regarding female modesty and sanctions against inadvertently exposing their bodies [21,23], particularly in low- and some middle-income countries which may have more limited sanitation options in place, lead girls and women to seek out alternative options for managing their menstruation and other sanitation needs. For example, girls and women may seek out locations under cover of darkness, such as near railroad tracks or in fields, with few options provided in societies that do not prioritize their gendered sanitation needs [24]. Consulting girls and women directly in order to understand why, for example, some may prefer to change menstrual materials in bathing shelters is essential, with cultural reasons being the rationale for some [5], and limited latrine design aspects, including the insufficient availability of privacy or water in bathing stalls $[14,20]$ or long waiting queues, being the rationale for others.

At the most basic level, girls and women around the world have distinct sanitation needs as compared to men, which is the product of their physiology, reproductive health processes, existing social norms, and vulnerability to violence. Girls and women generally use toilets more frequently and for a longer period of time than boys and men $[18,25]$, especially while managing their monthly menstruation, when pregnant, or during other periods of extended vaginal bleeding $[11,26]$. This may have design implications, such as a need for a larger stall space to adequately move around inside the cubicle more comfortably, additional stalls within a latrine block given the stigma or vulnerability to harassment from standing in long lines in peri-urban slum environments, or better lighting for nighttime usage.

In addition, girls and women frequently assume greater caretaker roles within their families, requiring them to bring children into toilets or to accompany children, elderly individuals, and family members with disabilities into toilets to support their management of sanitation needs. In some urban contexts (e.g., in urban slum environments in Uganda and Kenya), girls and women rely on the use of pay-for-service communal toilets. In addition to covering their own costs, women sometimes 
must cover the cost of their children's access to such toilets, adding an additional financial burden that may limit their own usage [6,9]. Furthermore, water, which is essential for cleaning both after defecating (as anal cleansing remains common in Asian contexts) and during menstruation, is also often inconveniently located from the placement of rural latrines (e.g., such as a water source being located a sizable distance from a toilet), resulting in additional stress for the procurement of water by girls and women prior to toilet usage $[1,3,8,27,28]$.

\section{Toilets and Health}

In relation to their physiology and overall health and wellbeing, girls and women have unique needs for convenient, safe, and accessible female-friendly toilet facilities. Over the course of their reproductive lifespans, adolescent girls and women have increased and fluctuating water and sanitation-related requirements as compared to men, linked to menstruation, pregnancy (e.g., post-partum bleeding, miscarriage, stress urinary incontinence), and other common health conditions such as those that involve increased vaginal bleeding (e.g., uterine fibroids, endometriosis). Research has found that the challenges posed by long public lines or other situations causing anxiety related to the inconvenient access to safe and clean toilets outside their homes help to create, among girls and women, a range of coping mechanisms with potential health consequences, such as reducing their intake of liquids or food [29-31]. Although there is a need for more rigorous research on these associations, dehydration and regulating urination may increase risks for urinary tract infections and chronic constipation [32-36].

The frequency of girls' and women's needs for adequate sanitation is often increased as compared to boys and men; at any given time, about a quarter of all adult women globally are menstruating, which required the frequent changing of menstrual materials (cloths, pads, tissues), often from two to four times a day $[35,37,38]$. Finding private and safe locations for menstrual hygiene management (MHM) is often challenging, especially for girls and women living in displacement camps or urban slums which are overcrowded and provide minimal privacy $[22,23,39]$. As noted earlier, the anxiety felt while trying to find a toilet, especially when outside of the home, can also result in girls and women refraining from conducting daily activities like visiting the market, workplace, or school $[5,7,14,23,40]$. Poor access to toilets in workplace contexts may impact their productivity, wellbeing, and attendance, especially during their menstruation, although to date minimal research has been conducted on this issue [40].

\section{Impact of Stigma and Cultural Beliefs on Sanitation Practices}

Girls and women also face a range of gender-related pressures with respect to the management of their own sanitation needs $[14,41,42]$. Societal pressures directly impact both when and where they can address their sanitation needs. Unlike males, girls and women often experience greater expectations to keep their bodies covered due to prevailing modesty norms mandating that girls and women not expose themselves [1,2,21,41]. In contrast, for example, boys and men, in the absence of sanitation facilities, sometimes choose to urinate in more public spaces with less stigma and taboo [41]. The modesty demands on females are more heightened for young or newly married women as their families may have strong concerns for protecting their reputation and perceived modesty $[1,14,36,43]$. A study conducted in Odisha, India found that women were concerned about "being seen urinating, defecating, entering or leaving toilets, bathing at menstrual onset or washing, drying and disposing of materials", because such actions were thought to be damaging to their own or their family's reputation and thus hurting their marital prospects $[14,29,43,44]$.

Negative cultural norms surrounding menstruation often limit girls' and women's daily mobility and engagement in society, such as not entering religious spaces $[45,46]$, not assisting with agricultural activities [46], or not cooking food and washing dishes [47-49]. Such beliefs precipitate into feelings of shame by girls and women and thus a heightened need to keep all management aspects of their periods and other vaginal bleeding as discreet as possible. There may also exist strong cultural beliefs 
regarding the disposal of menstrual waste, such as concerns of witchcraft being practiced if the used menstrual materials are seen by others, and the risk of diseases or infertility that might be caused by the burning of used menstrual materials, such as sanitary pads or cloths $[20,50]$. Because toilets may lack adequate or culturally acceptable disposal and waste management systems, girls and women may adopt approaches for secretly managing their menstrual waste, such as waking up before dawn to bury their menstrual waste under the cover of darkness $[1,5,47,50]$ or disposing of used menstrual materials (pads, cloths) directly into toilets or latrine pits $[20,23,50]$.

Such cultural beliefs are important to consider when designing female-friendly toilets given that they influence the acceptance and usage of a toilet facility. For example, a study conducted by WaterAid in urban slums and villages in India found that despite $63 \%$ of female survey respondents indicating access to a toilet, about $20 \%$ refused to use the toilet during menstruation due to fears of staining the toilet with blood, and due to the non-availability of disposal options [7]. As toilets are often one of the few available locations for girls and women to manage menstruation in a given context, it is essential to incorporate culturally appropriate disposal options as a core design component of a female-friendly toilet. Minimal evidence currently exists on appropriate strategies, best practices, and global consensus regarding disposal and waste management technologies and systems, especially ones that can be used in low-resource contexts or that incorporate the perspectives of girls and women. The failure to consider the implications of menstrual waste at the onset of constructing sanitation facilities, which is especially common during humanitarian response efforts, continues to be a costly mistake leading to pipe clogging, faster pit filling rates, and difficulties in emptying toilet cesspits and septic tanks $[5,20,21,50,51]$.

\section{Sanitation-Related Safety Risks and Gender-Based Violence}

Safety is another key concern that supports the need for a more widespread concept and uptake of a female-friendly toilet. Girls and women without access to convenient and safe toilets within their households may be dependent on public or communal facilities that create a heightened risk for violence or stress [24,52]. The journey to find a private toilet can be emotionally and physically taxing, requiring girls and women to traverse long distances through unsafe areas and during nighttime darkness with inadequate lighting on pathways or in stalls $[5,9,53]$. Girls and women may experience direct harassment from boys and men, including sexual assault while using communal or public toilet facilities $[9,25,54]$.

Safety with respect to sanitation may be even more challenging in overcrowded displacement camps $[5,55]$ and urban slum settings $[6,8,9]$ where privacy and lighting are frequently inadequate. A study conducted with refugees living in camps in Cameroon found that $99 \%$ of women did not feel safe using camp toilets, citing concerns regarding the risk of assault due to the lack of lighting and locks [55]. Fears of nighttime assault may lead girls and women to create makeshift toilets (e.g., the use of outdoor drains or buckets) $[6,10,14,56]$, refrain from consuming liquids $[30,44]$, wake at early hours (4:00-5:00 a.m.) to use toilets [5], or resort to using plastic bags for waste excretion ("flying toilets"), which are eventually thrown into the open or general waste streams $[6,9,57]$. Core design components of a female-friendly toilet must thus consider the location (distance, proximity to males) and conditions (e.g., lighting — both the surrounding area and inside the stalls) to ensure the acceptability and ultimate usage of these facilities by girls and women.

\section{Redefining the Concept of Female-Friendly Toilets}

The overarching objective of creating a new norm for the design and provision of female-friendly toilets is to ensure that girls and women feel confident, safe, and dignified in managing their daily sanitation. To address girls' and women's distinct sanitation needs, including the management of menstruation and other vaginal bleeding, more supportive design components should be incorporated into basic standards for the construction of female-friendly toilets (Figure 1). Furthermore, the actual 
placement (or location within a given context) of a female-friendly toilet should be perceived as having an equivalent importance to the type and quality of the facility being provided [42,58].

EXAMPLE OF A FEMALE-FRIENDLY TOILET
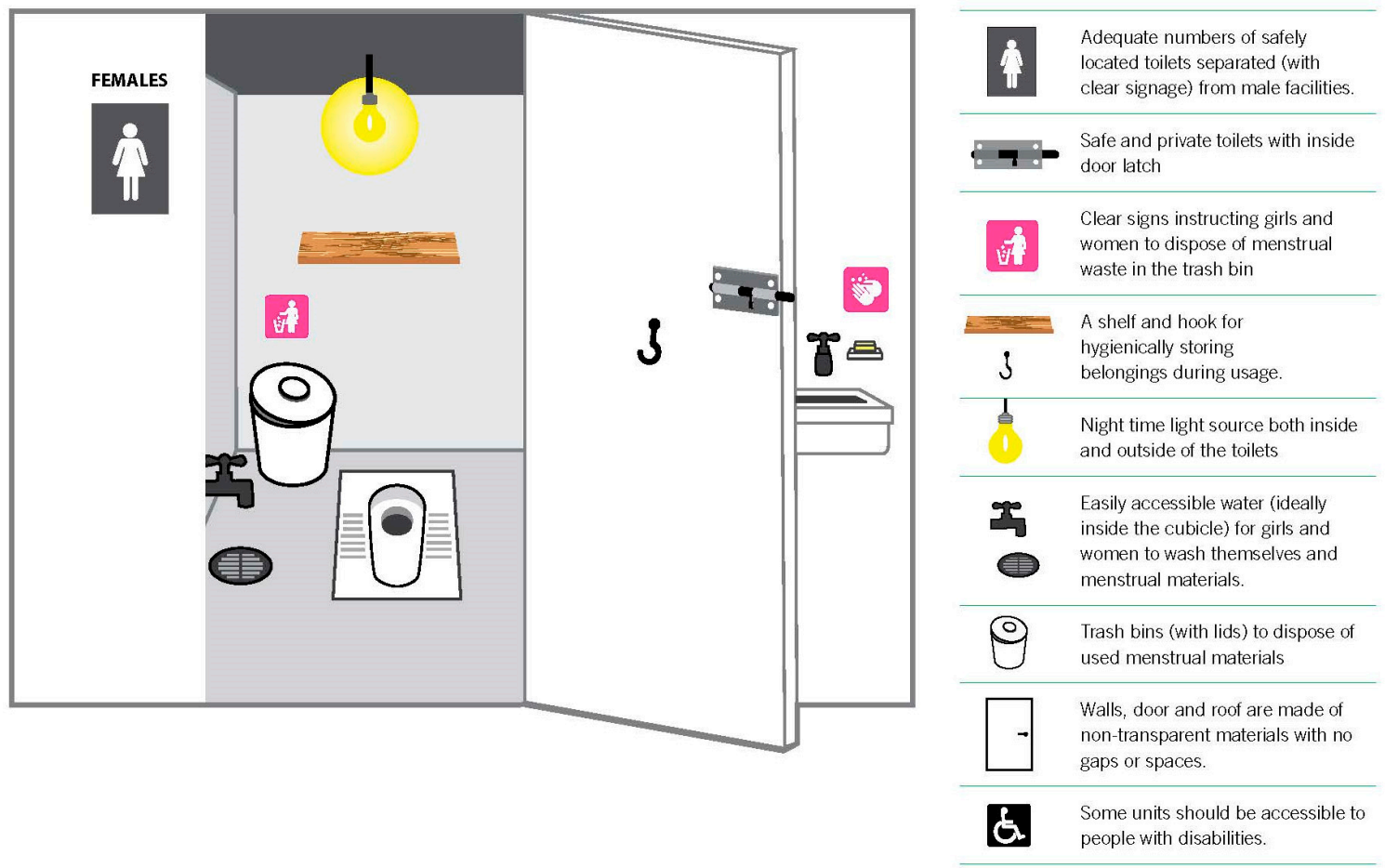

Figure 1. An example of a female-friendly toilet design for humanitarian contexts.

The above definition and design can be adapted to a range of development or humanitarian contexts, with implications for varying facility types (e.g., public, institutional, household) and sanitation practices, such as toilet design (e.g., pit latrine, pour-flush latrine, latrine with a septic tank), water source (e.g., tap, bucket, water vessel), or preferred disposal mechanism (e.g., chute, trash bin, incinerator). Additional supportive measures can be included, such as hooks or shelves inside a stall to enable girls and women to hygienically store bags containing menstrual supplies or clean menstrual cloths, rather than place them on the dirty ground or floor. The provision of a mirror is also useful, as it allows girls and women to check their clothing for blood stains. In addition, the space and layout of the toilet is important, including the provision of at least some stalls that provide ample space for both a female and an additional person requiring assistance with toileting (e.g., children or a disabled or elderly relative) [21,59]. In some privacy-scarce contexts, such as refugee camps, girls and women may also use toilets as locations for bathing or for washing menstrual cloths, thus requiring design considerations which accommodate for the discreet drainage of water containing blood.

Beyond the provision of a female-friendly toilet, operations and maintenance are essential for sustaining the infrastructure and functionality (or smooth functioning) of the design. This includes ensuring that water sources are available (e.g., buckets are filled or taps are working), trash bins for menstrual waste have covers and are routinely emptied (waste management systems), toilet stalls are regularly cleaned, locks, doors, and lights function as intended, adequate ventilation is available, and gender segregation rules (if necessary) are respected. Furthermore, it is critical to monitor that menstrual waste disposal practices (e.g., disposal into bins and not directly into toilets) are followed given the costly consequences of misuse. The latter often require continuous engagement and education in the community. Ultimately, the sustainability of female-friendly toilets remains dependent on the 
adherence to routine monitoring and evaluation of this infrastructure, both at the onset but also over time.

\section{Conclusions}

There are multiple recommendations regarding how to mainstream female-friendly toilets into water and sanitation efforts, which include the following. One, incorporate core components of female-friendly toilets into existing guidelines developed by key water, sanitation, and hygiene (WASH) actors, governments, international agencies (e.g., United Nations Children's Fund (UNICEF), United Nation's High Commissioner for Refugees (UNHCR)), donors, and non-governmental organizations. For example, adapt existing guidelines for community-led total sanitation (CLTS) programs to explicitly promote engagement with girls and women about their needs and preferences, including provisions for incorporating MHM [21]. Two, institute gender-disaggregated indicators which measure access and usage across the development and humanitarian sectors to effectively assess the actual impact and operational value of female-friendly toilet approaches. Three, ensure that national and global-level actors engage actively in breaking down ongoing discomfort about discussing female sanitation, both with the female populations they serve, and within professional networks and organizational teams.

This paper's aim of proposing a female-friendly toilet concept is to catalyze conversations among designers, policy makers, WASH practitioners, and other relevant actors about adapting toilets in their own contexts and operations, so that attention will be given to the key components essential for toilets that girls and women can safely and comfortably use. Mainstreaming the provision of female-friendly toilets, the lack of which is representative of ongoing societal gender discrimination, would have significant implications for meeting the Sustainable Development Goals (SDGs) regarding health, education, sanitation, economic empowerment, and gender.

Author Contributions: M.L.S. led the writing of the manuscript; D.C. and T.O. reviewed and provided technical input to the commentary content; M.S. provided overall guidance on the development and writing of the manuscript, including editorial support. All authors read and approved the final manuscript.

Acknowledgments: This research received no specific grant from any funding agency in the public, commercial, or not-for-profit sectors.

Conflicts of Interest: The authors declare no conflicts of interest.

\section{References}

1. Sahoo, K.C.; Hulland, K.; Caruso, B.A.; Swain, R.; Freeman, M.C.; Panigrahi, P.; Dreibelbis, R. Sanitation-related psychosocial stress: A grounded theory study of women across the life-course in Odisha, India. Soc. Sci. Med. 2015, 139, 80-89. [CrossRef] [PubMed]

2. Bisung, E.; Elliott, S.J. 'Everyone is exhausted and frustrated': Exploring psychosocial impacts of the lack of access to safe water and adequate sanitation in Usoma, Kenya. J. Water Sanit. Hyg. Dev. 2016, 6, 205-214. [CrossRef]

3. Hulland, K.; Chase, R.P.; Caruso, B.A.; Swain, R.; Biswal, B.; Sahoo, K.C.; Panigrahi, P.; Dreibelbis, R. Sanitation, stress, and life stage: A systematic data collection study among women in Odisha, India. PLoS ONE 2015, 10, e0141883. [CrossRef] [PubMed]

4. Mills, J.E.; Cumming, O. The Impact of Water, Sanitation and Hygiene on Key Health and Social Outcomes: Review of Evidence; United Nations Children's Fund (UNICEF) and the Sanitation and Hygiene Applied Research for Equity (SHARE) Consortium: London, UK, 2016.

5. Schmitt, M.L.; Clatworthy, D.; Ratnayake, R.; Klaesener-Metzner, N.; Roesch, E.; Wheeler, E.; Sommer, M. Understanding the menstrual hygiene management challenges facing displaced girls and women: Findings from qualitative assessments in Myanmar and Lebanon. Confl. Health 2017, 11, 19. [CrossRef] [PubMed]

6. Massey, K. Insecuity and Shame: Exploration of the Impact of the Lack of Sanitation on Women in the Slums of Kampala, Uganda. Master's Thesis, London School of Hygiene and Tropical Medicine, London, UK, 2011. 
7. Mahon, T.; Fernandes, M. Menstrual hygiene in South Asia: A neglected issue for WASH (water, sanitation and hygiene) programmes. Gend. Dev. 2010, 18, 99-113. [CrossRef]

8. Corburn, J.; Hildebrand, C. Slum Sanitation and the Social Determinants of Women's Health in Nairobi, Kenya. J. Environ. Public Health 2015, 2015, 209505. [CrossRef] [PubMed]

9. Amnesty International. Risking Rape to Reach a Toilet: Women's Experiences in the Slums of Nairobi, Kenya; Amnesty International: London, UK, 2010.

10. McFarlane, C.; Desai, R.; Graham, S. Informal urban sanitation: Everyday life, comparison and poverty. Ann. Am. Assoc. Geogr. 2014, 104, 989-1011. [CrossRef]

11. Anthony, K.H.; Dufresne, M. Potty parity in perspective: Gender and family issues in planning and designing public restrooms. J. Plan. Lit. 2007, 21, 267-294. [CrossRef]

12. Weiss-Wolf, J. Periods Gone Public: Taking a Stand for Menstrual Equity; Skyhorse Publishing Inc.: New York, NY, USA, 2017.

13. Granger, L. Putting Periods on the Agenda. Ms. Magazine, 15 February 2018. Available online: http: / / msmagazine.com/blog/2018/02/15/putting-periods-agenda/ (accessed on 23 August 2018).

14. Caruso, B.A.; Clasen, T.F.; Hadley, C.; Yount, K.M.; Haardörfer, R.; Rout, M.; Dasmohapatra, M.; Cooper, H.L. Understanding and defining sanitation insecurity: Women's gendered experiences of urination, defecation and menstruation in rural Odisha, India. BMJ Glob. Health 2017, 2, e000414. [CrossRef] [PubMed]

15. Zraick, K. It's not just about a tax: Why menstrual periods are also political. The New York Times, 22 July 2018. Available online: https:/ / www.nytimes.com/2018/07/22/health/tampon-tax-periods-menstruation-nyt. html (accessed on 23 August 2018).

16. Bobel, C. Menstrual Pads Can't Fix Prejudice. New York Times, 31 March 2018, p. SR6.

17. Jones, A. Periods, Policy and Politics: Menstrual Equity is the New Thing. Newsweek, 8 May 2017. Available online: https:/ / www.newsweek.com/periods-policy-and-politics-menstrual-equity-new-thing-596027 (accessed on 23 August 2018).

18. Tilley, E.; Bieri, S.; Kohler, P. Sanitation in developing countries: A review through a gender lens. J. Water Sanit. Hyg. Dev. 2013, 3, 298-314. [CrossRef]

19. House, S.; (Independent WASH Expert, Leicester, UK). Personal communication, 2018.

20. Sommer, M.; Schmitt, M.L.; Ogello, T.; Mathenge, P.; Mark, M.; Clatworthy, D.; Khandakji, S.; Ratnayake, R. Pilot testing and evaluation of a toolkit for menstrual hygiene management in emergencies in three refugee camps in Northwest Tanzania. J. Int. Humanit. Action 2018, 3, 6. [CrossRef]

21. Burt, Z.; Nelson, K.; Ray, I. Towards Gender Equality Through Sanitation Access; UN Women Headquarters: New York, NY, USA, 2016.

22. Sommer, M.; Schmitt, M.L.; Clatworthy, D.; Bramucci, G.; Wheeler, E.; Ratnayake, R. What is the scope for addressing menstrual hygiene management in complex humanitarian emergencies? A global review. Waterlines 2016, 35, 245-264. [CrossRef]

23. Parker, A.H.; Smith, J.A.; Verdemato, T.; Cooke, J.; Webster, J.; Carter, R.C. Menstrual Management: A Neglected Aspect of Hygiene Interventions. Disaster Prev. Manag. 2014, 23, 437-454. [CrossRef]

24. Sommer, M.; Ferron, S.; Cavill, S.; House, S. Violence, gender and WASH: Spurring action on a complex, under-documented and sensitive topic. Environ. Urban. 2014, 27, 105-116. [CrossRef]

25. Reed, B.J.; Coates, S.; Parry-Jones, S. Infrastructure for all: Meeting the Needs for Both Men and Women in Development Projects - A Practical Guideline for Engineers, Technicians and Projects Managers; Water, Engineering and Development Centre (WEDC) Loughborough University of Technology: Loughborough, UK, 2007.

26. Edwards, J.; McKie, L. Women's public toilets: A serious issue for the body politic. Eur. J. Women's Stud. 1996, 3, 215-230. [CrossRef]

27. Sommer, M.; Phillips-Howard, P.A.; Mahon, T.; Zients, S.; Jones, M.; Caruso, B.A. Beyond menstrual hygiene: Addressing vaginal bleeding throughout the life course in low and middle-income countries. BMJ Glob. Health 2017, 2, e000405. [CrossRef] [PubMed]

28. Biran, A.; Jenkins, M.W.; Dabrase, P.; Bhagwat, I. Patterns and determinants of communal latrine usage in urban poverty pockets in Bhopal, India. Trop. Med. Int. Health 2011, 16, 854-862. [CrossRef] [PubMed]

29. Gonsalves, G.S.; Kaplan, E.H.; Paltiel, A.D. Reducing sexual violence by increasing the supply of toilets in Khayelitsha, South Africa: A mathematical model. PLoS ONE 2015, 10, e0122244. [CrossRef] [PubMed]

30. Khanna, T.; Das, M. Why gender matters in the solution towards safe sanitation? Reflections from rural India. Glob. Public Health 2016, 11, 1185-1201. [CrossRef] [PubMed] 
31. Koner, K. Sanitation and hygiene of Darjeeling City: A crisis for women and adolescent girls. Space Cult. India 2018, 5, 89-105. [CrossRef]

32. Venugopal, V.; Rekha, S.; Manikandan, K.; Latha, P.K.; Vennila, V.; Ganesan, N.; Kumaravel, P.; Chinnadurai, S.J. Heat stress and inadequate sanitary facilities at workplaces an occupational health concern for women? Glob. Health Action 2016, 9, 31945. [CrossRef] [PubMed]

33. Mudey, A.B.; Kesharwani, N.; Mudey, G.A.; Goyal, R.C. A Cross-sectional Study on Awareness Regarding Safe and Hygienic Practices amongst School Going Adolescent Girls in Rural Area of Wardha District, India. Glob. J. Health Sci. 2010, 2, 225-231. [CrossRef]

34. Bapat, M.; Agarwal, I. Our needs, our priorities; women and men from the slums in Mumbai and Pune talk about their needs for water and sanitation. Environ. Urban. 2003, 15, 71-86. [CrossRef]

35. Das, P.; Baker, K.K.; Dutta, A.; Swain, T.; Sahoo, S.; Das, B.S.; Panda, B.; Nayak, A.; Bara, M.; Bilung, B.; et al. Menstrual hygiene practices, WASH access and the risk of urogenital infection in women from Odisha, India. PLoS ONE 2015, 10, e0130777. [CrossRef] [PubMed]

36. Fisher, J. For Her It's the Big Issue: Putting Women at the Centre of Water Supply, Sanitation and Hygiene. Water, Sanitation and Evidence Report; Water Supply and Sanitation Collaborative Council (WSSCC): Geneva, Switzerland, 2006.

37. Haque, S.E.; Rahman, M.; Itsuko, K.; Mutahara, M.; Sakisaka, K. The effect of a school-based educational intervention on menstrual health: An intervention study among adolescent girls in Bangladesh. BMJ Open 2014, 4, e004607. [CrossRef] [PubMed]

38. Omidvar, S.; Begum, K. Factors influencing hygienic practices during menses among girls from south India-A cross sectional study. Int. J. Collab. Res. Intern. Med. Public Health 2010, 2, 411-423.

39. van Eijk, A.M.; Sivakami, M.; Thakkar, M.B.; Bauman, A.; Laserson, K.F.; Coates, S.; Phillips-Howard, P.A. Menstrual hygiene management among adolescent girls in India: A systematic review and meta-analysis. BMJ Open 2016, 6, e010290. [CrossRef] [PubMed]

40. Sommer, M.; Chandraratna, S.; Cavill, S.; Mahon, T.; Phillips-Howard, P. Managing menstruation in the workplace: An overlooked issue in low- and middle-income countries. Int. J. Equity Health 2016, 15, 86. [CrossRef] [PubMed]

41. O'Reilly, K. Combining Sanitation and Women's participation in water supply: An example from Rajasthan. Dev. Pract. 2010, 20, 45-56. [CrossRef]

42. O'Reilly, K. Geography Matters: The Importance of Land, Water and Space in Sanitation Studies. wH2O J. Gend. Water 2012, 1, 7-9.

43. Greed, C. Taking Women's Bodily Functions into Account in Urban Planning: Sanitation, toilets, menstruation and biological differences. In Proceedings of the EnGendering Cities, Designing Sustainable Urban Environment, Rome, Italy, 25-26 September 2014.

44. Doron, A.; Jeffrey, R. Open Defecation in India. Econ. Pol. Wkly. 2014, 49, 72-78.

45. Khanna, A.; Goyal, R.S.; Bhawsar, R. Menstrual Practices and Reproductive Problems: A Study of Adolescent Girls in Rajasthan. J. Health Manag. 2005, 7, 91-107. [CrossRef]

46. Gottlieb, A. Sex, Fertility and Menstruation among the Beng of the Ivory Coast: A Symbolic Analysis. Africa 1982, 52, 34-47. [CrossRef] [PubMed]

47. Garg, S.; Sharma, N.; Sahay, R. Socio-cultural aspects of menstruation in an urban slum in Delhi, India. Reprod. Health Matters 2001, 9, 16-25. [CrossRef]

48. McMahon, S.A.; Winch, P.J.; Caruso, B.A.; Obure, A.F.; Ogutu, E.A.; Ochari, I.A.; Rheingans, R.D. 'The girl with her period is the one to hang her head' Reflections on menstrual management among schoolgirls in rural Kenya. BMC Int. Health Hum. Rights 2011, 11. [CrossRef] [PubMed]

49. Umeora, O.U.J.; Egwuatu, V.E. Menstruation in rural Igbo women of south east Nigeria: Attitudes, beliefs and practices. Afr. J. Reprod. Health 2008, 12, 109-115. [PubMed]

50. Scorgie, F.; Foster, J.; Stadler, J.; Phiri, T.; Hoppenjans, L.; Rees, H.; Muller, N. ‘Bitten By Shyness': Menstrual Hygiene Management, Sanitation, and the Quest for Privacy in South Africa. Med. Anthropol.-Cross Cult. Stud. Health Illn. 2015, 35, 161-176. [CrossRef] [PubMed]

51. International Federation of Red Cross and Red Crescent Societies (IFRC). Menstrual Hygiene: What's the Fuss? Piloting Menstrual Hygiene Management (MHM) Kits for Emergencies in Bwagiriza Refugee Camp, Burundi; IFRC: Geneva, Switzerland, 2013. 
52. Winter, S.C.; Barchi, F. Access to sanitation and violence against women: Evidence from Demographic Health Survey (DHS) data in Kenya. Int. J. Environ. Health Res. 2016, 26, 291-305. [CrossRef] [PubMed]

53. VanLeeuwen, C.; Torondel, B. Exploring menstrual practices and potential acceptability of reusable menstrual underwear among a Middle Eastern population living in a refugee setting. Int. J. Womens Health 2018, 10, 349-360. [CrossRef] [PubMed]

54. Day, M. Sexual Violence and Exploitation: The Experience of Refugee Children in Guinea, Liberia, and Sierra Leone. Geo. Immigr. Law J. 2001, 16, 735.

55. UN Women; IFORD; WSSCC. Menstrual Hygiene Management in Humanitarian Situations: The Example of Cameroon; Water Supply \& Sanitation Colloborative Council (WSSCC), UN Women and the Institute of Demographic Training and Research (IFORD): Geneva, Switzerland, 2018.

56. Adams, J. A Clean and Decent Life without WASH? The Impacts and Risks of Reduced WASH Funding for Syrian Refugees in Bekaa, Lebanon; Oxfam: Oxford, UK, 2018.

57. Lusambili, A. 'It is Our Dirty Little Secret': An Ethnographic Study of the Flying Toilets in Kibera Slums, Nairobi; STEPS Center: Brighton, UK, 2011.

58. Nawaz, J.; Lal, S.; Raza, S.; House, S. Oxfam experience of providing screened toilet, bathing and menstruation units in its earthquake response in Pakistan. Gend. Dev. 2010, 18, 81-86. [CrossRef]

59. De Lange, R.; Lenglet, A.; Fesselet, J.F.; Gartley, M.; Altyev, A.; Fisher, J. Keeping it simple: A gender-specific sanitation tool for emergencies. Waterlines 2014, 33, 45-54. [CrossRef]

(C) 2018 by the authors. Licensee MDPI, Basel, Switzerland. This article is an open access article distributed under the terms and conditions of the Creative Commons Attribution (CC BY) license (http://creativecommons.org/licenses/by/4.0/). 